\title{
Debates teóricos das relaçōes internacionais, política externa e a interação entre o nivel internacional e o doméstico
}

\author{
Discussion theory of international relations, foreign and interaction between the \\ international level and domestic
}

Debates teoría de las relaciones internacionales, la política exterior, y la interacción entre el nivel internacional y nacional

Tamara Silvana Menuzzi Diverio*

Luiz Gustavo Zuliani Da Silva**

Carlos Guilherme Adalberto Mielitz Netto***

\section{Resumo}

Este artigo tem por objetivo apresentar algumas contribuições das teorias de relações internacionais e dos principais autores que até hoje provocam debates nessa área de estudos. Neste espaço, serão destacadas algumas abordagens do tema, tais como o realismo e o neorrealismo, o liberalismo e o liberalismo neoinstitucional. Na sequência, será apresentada uma revisão da literatura e dos principais conceitos da análise de política externa, além da interação entre os níveis doméstico e internacional, utilizando a Teoria dos Jogos de dois níveis, de Putnam.

Palavras-chave: Política externa. Relações internacionais. Jogos de dois níveis.

\section{Introdução}

Cientistas políticos discutiram e indicaram teorias, buscando compreender os eventos e acontecimentos em relações internacionais. Os modelos teóricos desenvolvi-

Economista. Doutora em Desenvolvimento Rural.
Universidade de Cruz Alta e Universidade Regional
Integrada do Alto Uruguai e das Missões, campus
Frederico Westphalen. Docente do Mestrado Profis-
sional em Desenvolvimento Rural da Universidade
de Cruz Alta. Email: tdiverio@unicruz.edu.br
** Economista. Mestre em Desenvolvimento Regional
pela Universidade de Santa Cruz do Sul. Docente
do Departamento de Ciências Sociais e Aplicadas
da Universidade Regional Integrada do Alto Uru-
guai e das Missões, campus Frederico Westphalen.
E-mail: zuliani@uri.edu.br.
Doutor em Ciência Econômica pela Universidade
Estadual de Campinas. Docente associado da Uni-
versidade Federal do Rio Grande do Sul. E-mail:
mielitz@ufrgs.br

Recebido em 02/10/2015 - Aprovado em 28/02/2016 http://dx.doi.org/10.5335/hdtv.16n.1.6268 
dos acabaram possibilitando um avançado conhecimento, em face da abrangência e da percepção parcial do mundo, em diversas situações políticas ou momentos históricos. São muitos os modelos que almejam esclarecer os elementos que compõem a temática das relações internacionais. Sendo assim, há problemas na concepção de uma única teoria, pois existem muitas interpretações possíveis sobre o que representa e que objetivos tem esse ramo do conhecimento. Nesse sentido, o conjunto de teorias que procuram explicar as relações internacionais é excessivamente complexo.

Do estudo das relações internacionais, não se extrai apenas um único modelo de explicação, que seria aceito pelos diversos pesquisadores. A sistemática dos principais modelos teóricos parece mais lógica se analisada, sempre que possível, sob uma perspectiva lógico-histórica, pois os fatos históricos sugerem que, para determinadas ocasiões, algumas perspectivas teóricas são mais adequadas para o estudo das relações internacionais do que outras. Contudo, tal separação estanque é impraticável diante da realidade social que dinamiza os contornos teóricos (CARVALHO, 2007).

Na visão de Seitenfus,

[...] as relações internacionais (RI) definem-se como o conjunto de contatos que se estabelecem através das fronteiras nacionais entre grupos socialmente organizados (2004, p. 2).

Nesse sentido, são internacionais todos os fenômenos que transcendem as fronteiras de um Estado, fazendo com que os sujeitos, privados ou públicos, individuais ou coletivos, relacionem-se entre si. Esse discerni- mento aumenta tanto o foco a ser analisado quanto a quantidade de atores que tomam parte das relações internacionais. Assim sendo, descarta-se a ideia de que os estudos de relações internacionais seriam restringidos à análise da ação externa do Estado, pois se sabe que na arena internacional existem muitos atores envolvidos. O referido autor lembra ainda que a atuação externa dos Estados e dos diversos atores internacionais não deverá ser compreendida sem a devida análise das condições internas que a motivam, já que existe um grande vínculo entre a percepção ideológica de um governo e sua atuação internacional.

Inserindo-se nessa temática, este artigo apresenta uma revisão de literatura das teorias de relações internacionais e da análise de política externa, além das contribuições teóricas que tratam da interação entre os atores internacional e doméstico, a tomada de decisão e os grupos de interesses. Com isso, pretende-se compreender o aprofundamento das inter-relações entre atores domésticos e internacionais.

\section{Concepções teóricas clássicas das relações internacionais: realismo, neorrealismo, liberalismo e institucionalismo neoliberal}

Dentro da teoria das relações internacionais, há uma perspectiva denominada realismo político, também conhecida como realismo clássico, tradicional ou estatocêntrico. As origens dessa corrente estão no pensamento de Maquiavel (1469-1527), em especial, na sua obra O príncipe, e de Thomas 
Hobbes (1615), cuja principal obra é Leviatã. Esses autores são os maiores inspiradores do alargamento desse paradigma. ${ }^{1} \mathrm{O}$ realismo político sistematiza suas inquietações em torno de dois conceitos-chave: o poder e o conflito. A percepção da natureza humana é de uma visão do indivíduo como primordialmente egoísta e sedento de poder, logo, segurança, glória, prestígio são objetivos a serem perseguidos. Segundo essa teoria, os indivíduos são organizados em Estados, e esses agem de um modo unitário na busca de seu próprio interesse, definido em termos de poder.

A origem clássica do realismo é encontrada na obra História da Guerra do Peloponeso, que examina o conflito entre Atenas e Esparta, na Grécia. Tucídides (471-400 a.C.) é considerado o primeiro autor a tratar de um assunto central no estudo das relações internacionais: a guerra. Podem-se destacar algumas lições importantes deixadas por Tucídides: os Estados buscam elevar ao máximo seu poder, com a tendência de balancear esse poder, os Estados são conduzidos por seus próprios interesses e pela questão da segurança, a cooperação e a lei são secundárias, a hegemonia é baseada na legitimidade do Estado que detém poder econômico e militar, mas exerce sua hegemonia por meio de ações ideológicas que o legitimam enquanto hegemônico (SARFATTI, 2005).

Mingst (2009) observa que pelo menos quatro das premissas principais do realismo são encontradas na história de Tucídides. A primeira é que o Estado é o grande e principal protagonista na guerra e na política em geral, como demandam os realistas mais modernos. A segunda é que, como o Estado é o protagonista único, não há um protagonista subnacional tentando derrubar a decisão do governo ou subverter os interesses do Estado. A terceira é que os tomadores de decisão, que agem em nome do Estado, são protagonistas racionais, ou seja, Tucídides acreditava que os indivíduos são seres racionais e tomam decisões ponderando as forças e fraquezas de várias opções em relação à meta a ser alcançada. A quarta é que Tucídides, como os realistas contemporâneos, preocupava-se com questões de segurança, isto é, com a necessidade de o Estado proteger-se contra inimigos internos e externos.

Entre 354 e 430 a.C., o bispo e filósofo cristão Santo Agostinho acrescentou uma premissa fundamental ao realismo, argumentando que a humanidade é falha, egoísta e egocêntrica, embora não predestinada a ser assim, desse modo, Agostinho atribui a culpa da guerra a essas características básicas da humanidade.

Já a obra de Nicolau Maquiavel (1532), O príncipe, foi escrita no contexto e período histórico referentes à formação dos Estados na Europa Ocidental, e concentra-se na teoria do poder político e das relações dos poderes entre os Estados com base na observação dos comportamentos. Para Maquiavel, a responsabilidade e a conduta dos governantes estão desobrigadas de qualquer preceito moral, vale dizer, uma das características básicas do paradigma clássico encontra-se no pressuposto que afasta a conduta do Estado e de seus governantes de todo e qualquer princípio moral, tanto no campo interno como externo (OLIVEIRA, 2004).

Maquiavel deixou como legado para os realistas a ênfase na sobrevivência do Esta- 
do como ator, ou seja, um príncipe sem um Estado perde todo seu valor. Sendo assim, o poder se faz necessário, e o uso da balança de poder, assim como de alianças, é crucial para lidar com o desafio da segurança. Nogueira e Messari (2005) afirmam que a perspectiva realista destaca que Maquiavel queria lidar com o mundo real, e não com o mundo como deveria ser. Segundo essa leitura, para Maquiavel, a moralidade que orienta as ações dos indivíduos não se aplica, nem deveria orientar as ações do príncipe.

Por sua vez, Thomas Hobbes, em Leviatã, apresentou um estado de anarquia internacional, ou seja, uma deficiência de autoridade internacional, na qual os Estados contêm precárias regras ou normas. Desse modo, impera o estado de natureza e competição original, no qual a anarquia é fator definidor e a guerra uma probabilidade real (PECEQUILO, 2004).

Hobbes adentra na teoria do estado de natureza anárquico, marcado pelo Homo homini lúpus, no qual vive o ser humano sem regras e sem leis, sem igualdade e sem justiça imparcial, pois a sociedade é uma guerra de todos os homens contra todos os homens, na qual apenas o mais forte tem possibilidade de sobrevivência. Conforme Hobbes, na vida internacional, também não se encontra qualquer princípio de sociabilidade, uma vez que a vida internacional é dominada por três causas de discórdia: a competição, a desconfiança e a glória. Os Estados e os homens combatem-se pela competição, tentando uns impor o domínio sobre os outros, podendo, assim, obter a glória (OLIVEIRA, 2004). Na concepção dos realistas, a ausência de um soberano que tenha o monopólio do uso legítimo da força nas relações internacionais é comparável ao estado de natureza, de Hobbes.

Para os realistas, Tucídides, Maquiavel e Hobbes destacam elementos de sobrevivência, tais como poder, medo e anarquia internacional, que compõem as premissas centrais do realismo nas relações internacionais (NOGUEIRA; MESSARI, 2005).

Os realistas operam, portanto, a partir da hipótese central de que a política mundial desenvolve-se em uma anarquia internacional: um sistema sem uma autoridade predominante ou um governo mundial. $\mathrm{O}$ Estado é o ator relevante na política mundial e nas relações internacionais. Os outros atores (indivíduos, organizações internacionais, ONGs, etc.) são irrelevantes.

Sarfatti (2005) observa que, no realismo clássico, os Estados são essencialmente atores racionais que, para construir sua política externa, calculam coerentemente os custos e benefícios de todas as suas ações. Outro destaque é que há nessa perspectiva teórica uma hierarquia entre os assuntos importantes de relações internacionais, ou seja, a segurança nacional é a matéria mais relevante na ordem de preferência dos Estados. Desse modo, a segurança é vista como "alta políti$\mathrm{ca}^{\prime \prime}$, enquanto a economia e outros assuntos sociais são percebidos com uma importância reduzida e, portanto, como "baixa política".

O realismo clássico entende o conceito de poder político como processo de concentração e coerção em nível doméstico, e de processo de descentralização, conflitivo, em âmbito internacional, introduzindo a figura do Estado como unidade política, soberana e suprema (OLIVEIRA, 2004) 
Os realistas adotam o Estado como uma caixa-preta e o adaptam dentro do que chamam de modelo bola de bilhar. Isso leva os adeptos dessa perspectiva teórica a descartar os processos internos de tomada de decisão e as motivações políticas que levam os Estados a atuar no plano internacional. Os realistas avaliam que o Estado age de modo uniforme e homogêneo e em defesa do interesse nacional. A unicidade do Estado se expressa no fato de ele ser considerado no seu conjunto, mas atuando nas relações internacionais de maneira a representar o todo de maneira homogênea e uniforme. Observa-se que, nessa visão, a complexidade dos processos internos não é levada em consideração (NOGUEIRA; MESSARI, 2005).

Carvalho (2007) destaca que, frequentemente, a postura adotada pelos realistas no ambiente interno difere daquela assumida no cenário internacional. Os realistas observam a política externa como um elemento fundamental para a consecução de certos objetivos estratégicos e, como consequência, fazem uso dela para ações que não têm vínculo com as agendas internas. Nessa visão, a política interna e a política externa são esferas distintas na ação estatal, e o comportamento do Estado em matéria de política é sempre racional e atento aos interesses nacionais. Essa característica destaca-se em função da ausência de limites que o Estado exige para fazer valer seus interesses.

Perante as lacunas das teorias vigentes, houve uma reação intelectual, que tem como exemplo a análise crítica de Carr (1892-1982), que escreveu o livro Vinte anos de crise (1939), e, finalmente, essa reação intelectual foi complementada pelo trabalho de
Morgenthau (2003), que escreveu A politica entre as nações: a luta pelo poder e pela paz, publicado originalmente em 1948, logo após a Segunda Guerra Mundial. Morgenthau instituiu as bases teóricas do realismo moderno.

No que se refere a Carr (2001), duas características são principais em suas obras: o foco no Estado-nação como único ator relevante das relações internacionais e o foco no poder como motivador das ações dos Estados. Carr retoma as ideias de Maquiavel e complementa que a ética não pode ser vista como esfera independente da política ou como sua norteadora, mas acredita que os Estados são guiados por certo darwinismo político, no qual os mais fortes e mais bem preparados se mantêm no sistema internacional. Além disso, esse autor aponta que não é a moral o cerne da política internacional, e sim a questão de como se adaptar e sobreviver no sistema internacional. Ele define o poder em três categorias: o militar, considerado a expressão mais alta de poder (high politics), o econômico, que se submete ao poder militar e pode vir a serviço do poder político, no sentido dos interesses do Estado, e o poder sobre a opinião, ou seja, a arte da persuasão.

Por sua vez, Morgenthau (2003) solidificou a visão realista das relações internacionais, recuperada por Carr. Nogueira e Messari (2005) observam que as relações internacionais, em geral, e o realismo, em particular, podem ser claramente separados em períodos pré e pós-Morgenthau, pois, em sua obra, o autor organizou e deu consistência ao realismo como abordagem teórica das relações internacionais. 
Pecequilo (2004) lembra que demandas morais e idealistas não devem ser levadas em consideração na visão realista, pois a política internacional e a doméstica representam esferas separadas e de lógicas diferentes, ao passo que o Estado atua racionalmente, avaliando riscos e benefícios. A ordem internacional é sustentada pelo equilíbrio de poder, e Morgenthau define a diplomacia como um fator de relevância na condução dos Estados e suas interações no ambiente mundial.

Entre 1950 e 1970, abrem-se novos pontos de vista teóricos, e o domínio do realismo passa a ser rebatido. No final dos anos 1970, as propostas do neorrealismo foram apresentadas de forma clara em obras de destaque, como The Anarchical Society, de Hedley Bull (2002), e Theory of international relations, de Kenneth Waltz (1979). Ambos os autores tentaram refutar as críticas dirigidas ao modelo do realismo tradicional, principalmente no que se refere à centralidade do Estado como ator unitário e racional, destacando tanto a importância do poder do Estado no sistema internacional e o papel de subordinação dos atores não estatais, como também a importância dos grandes poderes na administração das relações internacionais. Tanto Bull quanto Waltz conservaram-se céticos quanto ao crescente movimento da interdependência, da globalização, dos processos econômicos transnacionais e de sua significação à agenda internacional (OLIVEIRA, 2004).

Dessa forma, na década de 1970, surge o neorrealismo ou realismo estrutural, como desafio às premissas clássicas. Surgem os níveis de análise ou três imagens, ${ }^{2}$ de Waltz
(1979), que afirma que todas as explicações sobre as causas da guerra podiam ser acomodadas na primeira imagem: a imagem do indivíduo, na segunda: a imagem do Estado, e na terceira: a imagem do sistema internacional. Isso significou uma renovação e, ao mesmo tempo, uma crítica ao realismo moderno. A diferença entre o realismo moderno e o neorrealismo está no nível de análise: o realismo moderno foca no Estado, enquanto o neorrealismo foca no sistema internacional (SARFATTI, 2005).

Nogueira e Messari $(2005$, p. 38) destacam que o objetivo de Waltz não era privilegiar uma imagem em detrimento das demais, mas, sim, sistematizar o estudo das relações internacionais e de suas principais fontes em termos científicos. A teoria de Waltz condiz com a revolução behaviorista ${ }^{3}$ que estava ocorrendo nas demais ciências sociais nos Estados Unidos, na mesma época.

Pecequilo (2004) observa que o neorrealismo de Waltz abre espaço para as interações interno-externas no processo de elaboração de políticas e tomada de decisão, mas essa teoria não avança muito na resolução dos dilemas relativos à cooperação dos Estados.

Nesse sentido, a teoria da política internacional de Waltz (1979) busca apresentar uma explicação científica para o sistema político internacional, cuja abordagem explicativa é bastante influenciada por modelos positivistas da economia. Segundo Waltz, a melhor teoria de relações internacionais é sistêmica e neorrealista, que enfoque a estrutura do sistema, as suas unidades interativas, seus atributos permanentes e dinâmicos. No realismo clássico, os líderes estatais 
e suas avaliações subjetivas das relações internacionais estão no centro das atenções. No neorrealismo, ao contrário, a estrutura do sistema, em particular a distribuição do poder relativo, é o aspecto analítico central. Os atores são menos importantes, porque a estrutura os obriga a agir de determinadas maneiras, ou seja, as estruturas determinam mais ou menos as ações dos atores.

De uma forma geral, críticas são feitas à teoria de Waltz, em face da rigidez do modelo e de seu caráter estático, principalmente porque o autor não se prende a analisar as perspectivas e os papéis dos novos atores nas relações internacionais. Ao contrário, fixa-se nas unidades estatais e sua distribuição de poder político-militar, consolidado pelo status quo, em detrimento das transformações globais da sociedade internacional (OLIVEIRA, 2004).

O foco de Waltz (1979) é na estrutura do sistema, e não nos seres humanos que criam ou operam o sistema. Nesse sentido, líderes estatais são prisioneiros da estrutura do sistema estatal, e suas lógicas determinísticas comandam suas políticas externas. Assim, não há espaço, na teoria de Waltz, para a formulação de uma política externa independente da estrutura do sistema. Waltz opera também com um conceito de interesse nacional, que defende que "cada Estado planeja o curso que servirá melhor a seus interesses" (1979, p. 113).

Desse modo, no final da década de 1960, e no decorrer da década de 1970, vários desafios se impuseram ao realismo como teoria dominante das relações internacionais. $\mathrm{Na}$ área acadêmica, passou-se a considerar novos atores não estatais na política interna- cional, como empresas multinacionais e organizações internacionais governamentais e não governamentais, isso levou ao questionamento de premissas básicas do realismo. Igualmente, surgiram críticas à separação entre política doméstica e política internacional bem como à divisão entre high e low politics (alta política, relativa à segurança, e baixa política, referente a temas econômicos, tecnológicos, etc.) e à primazia da primeira em relação à segunda. Começou a se falar da exagerada ênfase dos realistas na questão da guerra em detrimento de outras questões de política internacional, e surgiram críticas ao excesso de ênfase no conflito em detrimento da cooperação e da interdependência.

O livro de Robert O. Keohane e Joseh S. Nye Jr. (1977), Power and independence, foi emblemático a esse respeito. De acordo com os autores, a "interdependência complexa" do pós-guerra é qualitativamente diferente dos tipos anteriores de interdependência. ${ }^{4}$ Antes disso, as relações internacionais eram coordenadas pelos líderes de Estado, que lidavam com outros líderes, e o uso da força militar sempre foi uma opção no caso do conflito entre eles. A "política superior" da segurança e da sobrevivência tinha prioridade sobre a "política inferior" da economia e das questões sociais (KEOHANE; NYE, 1977, p. 23).

Sob condições de interdependência complexa, contudo, a situação não é mais a mesma por duas razões: primeiro, as relações atuais entre os Estados não são somente ou basicamente interações entre líderes de Estados, há relações em níveis muito variados por meio de muitos atores e de diversos departamentos de governo; segundo, há um grande número de relações transna- 
cionais entre indivíduos e grupos externos ao Estado; e, além disso, a força militar é um instrumento de política menos útil sob condições de interdependência complexa (JACKSON; SORENSEN, 2007). Consequentemente, as relações internacionais assim se tornam mais parecidas com a política nacional: “Questões diferentes geram coalizões diferentes, ambas dentro de governos e entre governos, e envolvem diversos graus de conflito" (KEOHANE; NYE, 1977, p. 25). Na maioria desses conflitos, a força militar é irrelevante. Portanto, recursos de poder, além das armas, como habilidade de negociação, passam a ter suma importância. Por fim, sob uma interdependência complexa, os Estados se preocupam mais com a "política inferior" do bem-estar e menos com a "política superior" da segurança nacional (NYE, 1993; KEOHANE; NYE, 1977, p. 24-26).

Assim sendo, desde a década de 1970, o liberalismo passa por um renascimento sob a rubrica de institucionalismo liberal. Diferentemente dos liberais clássicos, os institucionalistas neoliberais não acreditam que os indivíduos cooperem naturalmente, em razão de uma característica inata da humanidade. Para os institucionalistas neoliberais, a cooperação emerge porque, para protagonistas que mantêm interações contínuas mútuas, a cooperação é do interesse de cada um. Instituições podem ser estabelecidas e afetar as possibilidades de cooperação, mas não as garantem.

Pecequilo (2004) lembra que assim como as discussões sobre o neorrealismo dominam os anos de 1970, as obras de Keohane e Nye, a partir da introdução de conceitos como interdependência e transnacionaliza- ção, tornam-se recorrentes no campo liberal. Essas visões são conhecidas como liberal institucionalismo, neoliberalismo ou paradigma da interdependência.

Os neoliberais compartilham antigas ideias liberais sobre a possibilidade de progresso e mudança, mas rejeitam o idealismo. Ademais, tentam formular teorias e aplicar novos métodos científicos. Sendo assim, o debate entre liberalismo e realismo continuou, mas passou a se basear na configuração internacional pós-1945 e na persuasão metodológica behaviorista (JACKSON; SORENSEN, 2007).

Para Keohane e Nye (1977), as relações entre os Estados ocidentais caracterizam-se por uma complexa interdependência: há muitas formas de conexões entre as sociedades, além das relações políticas dos governos, como elos transnacionais entre corporações de negócios. Também há uma ausência de hierarquia entre questões, a segurança militar não domina mais a agenda, não sendo mais usada como instrumento de política externa.

De acordo com Keohane e Nye (1977), a evolução da política internacional, desde 1945, e as estruturas multilaterais, construídas para organizar as relações entre os Estados nos mais diversos campos, incrementaram as possibilidades de cooperação entre as nações, reduzindo a incerteza e aumentando a transparência nas relações interestatais. Com base nesses mecanismos facilitadores, explicam os autores que o conflito passa a ser secundário diante da cooperação, uma vez que os Estados começam a dar preferência a esse âmbito institucional e a mudar a natureza de seu comportamento, voltado apenas para o conflito. Com isso, é 
estabelecido um conjunto claro de regras e princípios, facilitando a ação coletiva. Além de participarem em Organizações Internacionais Governamentais, os Estados também apoiam a criação de regimes, regulando suas relações.

Para Keohane (1989), de um ponto de vista neoliberal, os atores não estatais são considerados complacentes para a concepção das relações internacionais. Todos os atores internacionais que não são os Estados, como as empresas multinacionais (Empresas Transnacionais - ETNs, Organizações Internacionais não Governamentais - OINGs e Organizações Internacionais Governamentais - OIGs), são considerados atores não estatais das relações internacionais.

Cada dia mais ocorre o aumento de dependência e interdependência entre os Estados, que podem depender da comunicação internacional, da ajuda humanitária ou mesmo de arranjos comerciais internacionais. Nesse sentido, pode ocorrer o aumento da capacidade de influência de alguns governos, pois eles podem usar as organizações transnacionais para manipular os seus interesses.

Sarfatti (2005) afirma que o neoliberalismo é a primeira teoria de relações internacionais a oferecer um papel destacado aos atores transnacionais na política internacional. Obviamente que as relações transnacionais sempre existiram, sobretudo desde meados dos séculos XIX e XX, mas essas semelhanças, hoje, são díspares, dada a multiplicação dos atores não estatais, de fóruns de negociação internacional, além do efeito da revolução da tecnologia de informação e comunicação, que faz com que as sociedades estejam mais conectadas e mais interdependentes.
Cabe observar também que, cada vez mais, as relações econômicas e sociais se aprofundam entre os Estados, causando um aumento da interdependência entre eles, fazendo com que os objetivos econômicos e de segurança se entrelacem.

Moravcsik (1997) expôs uma reformulação da teoria liberal que visa ser "não ideológica" e "não utópica". O autor explica que os atores fundamentais na política internacional são indivíduos racionais e grupos privados, além do fato de que as políticas dos Estados representam o que os indivíduos e os grupos da sociedade e dentro do aparato estatal desejam. Portanto, a política governamental reflete as preferências de associações diferentes de grupos e indivíduos na sociedade nacional.

Os esforços de Moravcsik (1997) demonstram a tentativa de fornecer uma "reformulação geral de uma teoria liberal positiva" com base em fortes premissas liberais. O autor propõe que, contemporaneamente, o liberalismo seja baseado em suposições, tais como a primazia dos atores sociais, isto é, são os indivíduos e os grupos privados que se relacionam de forma racional e, portanto, são avessos a riscos e tendem a se organizar de forma coletiva a fim de promover os seus interesses ante a sociedade.

O ambiente social é entendido como naturalmente conflituoso, dados os interesses distintos dos indivíduos. Assim, o exame das relações internacionais tem o seu nível de análise no indivíduo que, por definição, comporta-se racionalmente, buscando satisfazer suas preferências de modo a maximizar os benefícios e minimizar os custos. Desse modo, este estudo leva em consideração 
que as políticas doméstica e internacional estão frequentemente interligadas. Na próxima seção, apresenta-se os autores que levam em consideração tais vínculos.

\section{A análise da política externa e a interação entre os níveis doméstico e internacional}

Na literatura sobre relações internacionais, há, muitas vezes, confusão no sentido de apontar política externa como sinônimo de relações internacionais. Para Cervo,

[...] relações internacionais correspondem a um conceito mais amplo, uma vez que incluem a política exterior que, em ordem decrescente de abrangência, inclui a diplomacia $(2008$, p. 8).

Oliveira (2005) acrescenta que as relações internacionais são uma área, por excelência, que representa os interesses do Estado no plano internacional e que tem como objetivo último buscar as satisfações do Estado, seja para a sua sobrevivência seja para a satisfação dos interesses de seus membros.

Hill define política externa como "a soma das relações oficiais externas conduzidas por um ator independente, geralmente um Estado, nas relações internacionais" (2003, p. 3, tradução nossa). No plano das relações internacionais, há a aceitação consensual de que os Estados são os atores legítimos na promoção dos interesses dos cidadãos, das empresas e dos conglomerados que estão dentro do seu território (OLIVEIRA, 2005). Para Oliveira, ainda que a interação entre os Estados esteja cada vez mais agregando a participação de organizações não governa- mentais, de empresas e/ou de grupos sociais, a política externa de um país corresponde à atuação do Estado na defesa do conjunto dos interesses dessas instituições.

Um fator importante além dos interesses do Estado é a capacidade que cada Estado detém de convencer os outros a aceitar as suas posições ou, em termos mais claros, o poder que cada Estado dispõe para a imposição de seus interesses. Na busca de promover seus interesses, existe um constante processo negociador que permite a atuação de diferentes Estados (OLIVEIRA, 2005).

A análise de política externa é como o estudo do comportamento e da prática das relações entre diferentes atores, principalmente os Estados, no sistema internacional. Fazem parte do conteúdo de análise de política externa a diplomacia, a inteligência, as negociações comerciais e os intercâmbios culturais.

No intuito de compreender as articulações dos atores domésticos sobre uma negociação internacional, será utilizada como método de análise a teoria dos jogos de dois níveis, de Robert Putnam (1988).

Putnam (1988) começa a discutir a relação entre o doméstico e o internacional no fim dos anos 1980, em seu trabalho intitulado Diplomacy and domestic politics: the logic of two-level games. Este estudo dá o passo inicial para outras pesquisas voltadas para a integração das arenas interna e externa em processos de negociação internacional. Para Putnam (2010), a política doméstica e as relações internacionais estão vinculadas. Essa vinculação é resultado da aproximação, relativamente recente e sistemática, das consequências da democracia sobre relações en- 
tre assuntos domésticos e internacionais na política externa.

$\mathrm{O}$ autor afirma que uma concepção mais adequada dos determinantes domésticos da política externa e das relações internacionais deve enfatizar as lutas políticas. A esse respeito, complementa que:

A luta política de várias negociações internacionais pode ser utilmente concebida como um jogo de dois níveis. No nível nacional, os grupos domésticos perseguem seus interesses pressionando o governo a adotar políticas favoráveis a seus interesses e os políticos buscam o poder constituindo coalizões entre os grupos. No nível internacional, os governos nacionais buscam maximizar suas próprias habilidades de satisfazer as pressões domésticas, enquanto minimizam as consequências adversas das evoluções externas. Nenhum dos dois jogos pode ser ignorado pelos tomadores de decisões (PUTNAM, 2010, p. 151).

Segundo Putnam (2010), os poderes executivos têm função principal nas mediações das pressões internacionais e domésticas pelo fato de estarem diretamente expostos a ambas as esferas. Desse modo, o líder que não consegue satisfazer seu ambiente doméstico arrisca-se a ser privado de seu posto. $\mathrm{O}$ autor divide o processo em dois estágios: o da negociação e o da ratificação. O estágio da negociação, nível I, leva a um acordo provisório e, na fase da ratificação, nível II, ocorrem as discussões entre os grupos domésticos de apoio sobre confirmar ou não o acordo. De acordo com Putnam, “[...] é bem provável que haja consultas prévias e barganhas no nível II com o objetivo de elaborar uma posição inicial para o nível I" (2010, p. 153).

Assim, a necessidade de confirmação do nível II afeta as barganhas no nível I, e o processo, em muitas negociações, pode ser dinâmico, uma vez que os negociadores tentam diversos acordos e consultam os pontos de vista de suas bases. Para Putnam, “[...] os atores no nível II podem representar agências burocráticas, grupos de interesses, classes sociais ou mesmo a 'opinião pública'" (2010, p. 153).

Com a metáfora do jogo de dois níveis, o autor analisa o fracasso dos acordos internacionais. De acordo com essa teoria, o governo é pressionado pela necessidade de atender demandas domésticas e, assim, obter apoio às suas decisões. Para Putnam (1988), a cooperação internacional pode avançar ou se limitar conforme o poder de veto, ou o apoio de atores internos às decisões a respeito dos acordos internacionais.

O referido autor acredita ainda que movimentos no plano internacional são capazes de intervir no ambiente doméstico do ator negociador e de flexibilizá-lo, aumentando assim as possibilidades de que os oponentes possam tirar dele concessões mais expressivas. Conforme esclarece Putnam (1988), em negociações internacionais, mais especificamente no plano externo, há países que lutam para obter mais vantagens comerciais para si. Já no plano interno, existem grupos de interesse que pressionam o governo para que ele adote medidas que lhes favoreçam. Desse modo, na teoria dos jogos de dois níveis, os chefes de governo estão posicionados estrategicamente entre dois tabuleiros: um formado pela política doméstica e o outro, pelas negociações internacionais.

Putnam (2010) acredita que o negociador internacional acaba sofrendo pressão de determinados grupos de interesse domésti- 
cos, que têm preferências diferentes uns dos outros. Com isso, como explica o autor, o interesse nacional acaba não sendo definido de maneira exclusiva pelo poder central (Executivo), pois acaba sendo o resultado do próprio debate interno entre os diversos poderes, tais como Legislativo, Executivo e Judiciário, grupos de interesse e opinião pública.

Para Putnam (2010), quando os custos e os benefícios de um acordo proposto são relativamente concentrados, é razoável esperar que grupos domésticos, cujos interesses sejam mais afetados, busquem exercer uma influência especial no processo de ratificação. Desse modo, a composição de grupos domésticos ativos no nível II também varia com o grau de politização do assunto.

Essa teoria mostra a heterogeneidade do ambiente interno e dá destaque ao papel dos atores. Putnam lembra que

[...] a natureza das questões "homogêneas" modifica-se ao compará-las com os casos em que as preferências dos grupos domésticos são mais heterogêneas, assim, qualquer acordo do nível I atinge desigualmente cada um dos grupos envolvidos (2010, p. 158).

Cabe ressaltar que, ainda de acordo com Putnam (2010), diferentemente das teorias estatocêntricas, a abordagem da metáfora dos jogos de dois níveis aceita a inevitabilidade do conflito doméstico em relação às exigências do interesse nacional. Isto é, essa perspectiva teórica reconhece que os tomadores de decisão lutam para harmonizar ao mesmo tempo os ambientes domésticos e internacionais.

Dentro da linha de pensamento de Putnam, vale destacar o interesse do segundo nível em participar da formulação dos rumos da política externa. Como explica o autor, para o negociador, o suporte do nível II também é muito importante, visto que auxilia na sua argumentação frente aos demais negociadores.

Por fim, é preciso destacar que, neste estudo, assume-se que políticas domésticas e relações internacionais são intrinsecamente correlacionadas. A posição internacional de um país exerce impacto em suas questões domésticas, e essa, por sua vez, depende do comportamento desse país no nível internacional.

\section{Considerações finais}

Embora se reconheça que existam inúmeros fatores domésticos e internacionais que podem influenciar o comportamento da política externa, essas influências são obrigatoriamente canalizadas pelo aparato político de um governo que identifica, decide e executa a política externa. Ao analisar a política externa, é necessário aprender sobre como as decisões de política externa são tomadas, obter informações sobre as intenções e estratégias dos governos e, principalmente, como as definições da situação são transformadas em ação.

Sendo assim, o processo de tomada de decisões, por sua parte, vincula-se com a dinâmica decisória. Dele participam atores governamentais e não governamentais do país e do exterior, em uma sequência temporal que se inicia no momento em que uma conjunção de estímulos externos e internos requer a tomada de uma decisão determinada até que ela seja efetivamente adotada. 
Com o desenvolvimento do estudo das teorias de decisão, produziu-se uma mudança fundamental pelo fato de a atenção não se dirigir aos Estados, enquanto abstrações, ou a governos como blocos monolíticos e unidos ante ao exterior, mas aos atores decisórios de política externa, enquanto seres humanos submetidos a diferentes pressões e influências.

Logo, segundo Oliveira e Lessa (2006), para melhor entender a política exterior de um Estado, atualmente, torna-se necessário assimilar não apenas a ligação existente entre as relações internacionais e a política interna, mas também analisar o funcionamento das instituições domésticas de um país, ou seja, além dos fatores globais, o comportamento externo de um país é determinado também por condicionantes domésticos. Cada vez mais, os grupos de interesse domésticos se dão conta de que as decisões dos formuladores de estratégias de política externa incidem diretamente sobre suas realidades.

Conforme Lafer (2001), transformar necessidades internas em possibilidades externas, o que é a essência da política externa, é mais necessário do que nunca nas configurações atuais do sistema internacional. As demandas e interesses dos diferentes grupos do nível doméstico chegam à arena internacional nem sempre por via direta, muitas vezes nem cruzam a fronteira entre o interno e o externo. Para os grupos políticos e sociais domésticos, cujos objetivos lograram transpassar o nível interno, é certo que foi preciso exercer o poder de barganhar, fazer alianças, pressionar e, de alguma forma, estender a sua influência sobre o processo decisório.

\section{Abstract}

This article aims to present some contributions of international relations theories and major authors that still provoke debates in this field of study. In this space, some approaches will be highlighted belonging to this area, such as realism and neorealism, liberalism and neo-institutional liberalism. Following a review of the literature and the main concepts of foreign policy analysis will be presented in addition to the interaction between the domestic and international level, using the Theory of Two-Level Games, Putnam.

Keywords: Foreign policy. International relations. Game two levels.

\section{Resumen}

Este artículo tiene como objetivo presentar algunas aportaciones de las teorías de las relaciones internacionales y los principales autores que todavía provocan debates en este campo de estudio. En este espacio, algunos enfoques serán destacados pertenecientes a esta área, como el realismo y el neorrealismo, el liberalismo y el neoliberalismo-institucional. Después de una revisión de la literatura y de los principales conceptos de análisis de la política exterior se presentará, además de la interacción entre el nivel nacional e internacional, utilizando la Teoría de los dos Level Games, Putnam.

Palabras clave: Política exterior. Relaciones internacionales. Juego de dos niveles. 


\section{Notas}

1 Série de postulados fundamentais sobre o mundo, que concentram a atenção do estudioso sobre certos fenômenos, determinando sua interpretação (KHUN 1988 apud LARRAÑAGA, 2008, p. 129).

2 Waltz classificou as teorias de relações internacionais em categorias, e as chamou também de imagens.

3 Behaviorismo: expressão que significa comportamento ou conduta e faz referência à doutrina que analisa o comportamento, ou seja, as atitudes e as reações dos diferentes atores. Desenvolveu-se como uma reação aos excessos do realismo, substituindo os postulados imprecisos e intuitivos daquele e procurando uma interpretação científica capaz de responder às complexidades das relações internacionais. O behaviorismo pretendia deslocar o foco da prescrição, a indagação ética e a ação para a descrição, a explicação e a verificação dos fatos (LARRAÑAGA, 2008, p. 135).

4 Keohane e Nye (1977) indicam que dependência significa que o estado dos Estados é determinado largamente por forças externas, enquanto interdependência é uma situação caracterizada por efeitos recíprocos entre países ou entre atores de diferentes países, ou simplesmente o estado de mútua dependência. Quando há um alto grau de interdependência, os Estados tendem a estabelecer instituições internacionais para lidar com problemas comuns. Ao fornecer informações e reduzir os custos das relações interestatais, as organizações conseguem promover a cooperação através das fronteiras.

\section{Referências}

CARR, E. H. Vinte anos de crise: 1919-1939: uma Introdução ao estudo das relações internacionais. Trad. Luiz Alberto Figueiredo Machado. 2. ed. Brasília: Editora UnB; Instituto de Pesquisa de Relações Internacionais; Imprensa Oficial do Estado de São Paulo, 2001.

CARVALHO, L. A. Introdução ao estudo das relações internacionais. 2. ed. São Paulo: IOB Thomson, 2007.

CERVO, A. L. Inserção internacional: formação dos conceitos brasileiros. São Paulo: Saraiva, 2008.

HILL, C. J. The changing politics of foreign policy. New York: Palgrave Macmillan, 2003.
JACKSON, R. H.; SORENSEN, G. Introdução às relações internacionais: teorias e abordagens. Rio de Janeiro: Zahar, 2007.

KEOHANE, R. O.; NYE, J. S. Power and interdependence. New York: Longman, 1977.

LAFER, C. A importância do setor privado nas negociações para a Alca. In: SEMINÁRIO ALCA: AMEAÇAS OU OPORTUNIDADES?, 2001, São Paulo. Artigos... São Paulo: Amcham Brasil, 2001. Disponível em: <http://www2. mre.gov.br/Alca/Artigos/Dis_laf100401. htm>. Acesso em: 25 set. 2014.

LARRAÑAGA, F. A. Introdução às relações internacionais. São Paulo: Aduaneiras, 2008.

MINGST, K. A. Princípios de relações internacionais. Rio de Janeiro: Elsevier, 2009.

MORAVCSIK, A. Taking preferences seriously: a liberal theory of international politics. International Organization, Toronto, v. 51, n. 4, p. 513-553, 1997.

MORGENTHAU, H. A politica entre as nações: a luta pelo poder e pela paz. Brasília: Editora UnB, 2003.

NOGUEIRA, J. P.; MESSARI, N. Teoria das relações internacionais: correntes e debates. Rio de Janeiro: Elsevier, 2005.

NYE JR., J. S. Understanding International Conflicts: an introduction to Theory and History. 4. ed. New York: Logman, 2003.

OLIVEIRA, H. A. Politica externa brasileira. São Paulo: Saraiva, 2005.

OLIVEIRA, H. A.; LESSA, A. C. (Org.). Relações internacionais do Brasil: temas e agendas. São Paulo: Saraiva, 2006. v. 1.

OLIVEIRA, O. M. Relações internacionais: estudos de introdução. 2. ed. Curitiba: Juruá, 2004.

PECEQUILO, C. S. Introdução às relações internacionais: temas, atores e visões. 5. ed. Petrópolis: Vozes, 2004.

PUTNAM, R. Diplomacia e política doméstica: a lógica dos jogos de dois níveis. Revista de So- 
ciologia Política, Curitiba, v. 18, n. 36, p.147-174, jun. 2010. Disponível em: <http://www.scielo. br/scielo.php?script=sci_arttext\&pid=S0104$-44782010000200010 \& \operatorname{lng}=$ en\&nrm $=$ iso $>$. Acesso em: 9 ago. 2014.

Diplomacy and domestic politics: the logic of two-level games. International Organization, Toronto, v. 42, n. 3, p. 427-461, 1988.

SARFATTI, G. Teorias de relações internacionais. São Paulo: Saraiva, 2005.

SEITENFUS, R. A. S. Relações internacionais. Barueri: Manole, 2004.

WALTZ, K. N. Theory of international politics. Nova York: McGrill, 1979. 